\title{
“MULHER E HUMOR”: UMA ANÁLISE DISCURSIVA DAS PIADAS DO JORNAL DAS MOÇAS DA DÉCADA DE 50
}

\author{
Victória da Silva Santana Araújoº ; Palmira Virgínia Bahia Heine ${ }^{2}$ \\ 1. Bolsista PIBIC/CNPq, Graduanda em Letras Vernáculas, Universidade Estadual de Feira de Santana, e-mail: \\ victoriaraujo03@gmail.com \\ 2. Orientadora, Departamento de Letras e Artes, Universidade Estadual de Feira de Santana, e-mail: pavibheine@ gmail.com
}

PALAVRAS-CHAVE: Piadas; Discurso; Mulher; Jornal das Moças.

\section{INTRODUÇÃO}

O período intitulado Anos Dourados compreendeu o intervalo entre os anos de 1946 e 1964. Esse período vai ser marcado por transformações político-econômicas principalmente no que concerne o quartel dos anos 50. O desenvolvimento brasileiro arranca em aceleração: a urbanização ganha mais fôlego e a industrialização se faz mais presente do que nunca, alavancando o consumo.

Aumentam-se, com a modernização brasileira, as vagas no mercado de trabalho e, para as mulheres, surgem oportunidades de emprego com o advento do setor terciário, bem como, segundo Pinsky (2014), surgem trabalhos considerados femininos, aumentando a demanda empregatícia. No entanto, concepções tradicionais ainda são mantidas envolvendo mudanças irrisórias nos modelos sociais dominantes. Mesmo com a possibilidade de "independência financeira da mulher, os ideais de casamento e moral sexual continuam em voga. A família ainda mantém o modelo conjugal e o principal mantenedor e chefe familiar é a figura masculina. O trabalho masculino é a principal fonte de renda dos recursos familiares e domésticos e à mulher cabe o papel ao qual foi destinada: a rainha do lar, responsável por manter a ordem doméstica e dedicar-se preferencialmente a manutenção do lar e dos filhos, bem como cuidar do marido.

A Revista Jornal das Moças servirá como difusor da ideologia dominante e principal mantenedora da ordem social e familiar, uma vez que era usada como aliada na educação das moças. Sendo uma das revistas mais populares no Brasil e ocupante do primeiro lugar na imprensa feminina durante muito tempo, vai ditar regras comportamentais e estabelecer os perfis femininos adequados e inadequados na época. $\mathrm{O}$ modo de abordagem e as temáticas dos artigos propagam a ideologia dominante do que é "ser mulher", ideologia esta que se materializa nos discursos produzidos pela revista a partir das materialidades que o constituem.

Uma dessas materialidades, que será o escopo da análise de dados do artigo, são as piadas que compõem o Jornal das Moças. Nomeada Troças e Traços, a seção de piadas era fixa, oferecendo às leitoras, toda semana, chistes de variadas temáticas, algumas mais regulares que outras. Mesmo destinada ao público feminino, não é absurdo encontrar piadas que ridicularizam e inferiorizam as mulheres através do humor. Segundo Pinsky (2014), as mulheres são raramente representadas com característica positivas, sendo representadas depreciativamente.

Enfatiza-se aqui a relevância da utilização do gênero piada a nível das análises. Possenti (1998), argumenta que o gênero é um material de extrema importância para as Condições de Produção, além de considerar que as piadas veiculam uma ideologia que reproduzem os valores arraigados na sociedade, sendo aliado na investigação de determinada posição ideológica. Logo, entende-se as piadas como "peças linguísticas" sobre as quais é possível verificar o funcionamento ideológico, procurando analisar como, sob a máscara do divertimento e trivialidade, tais piadas constroem sentidos sobre a feminilidade.

\section{MATERIAL E MÉTODOS OU METODOLOGIA (ou equivalente)}


A metodologia para a constituição da pesquisa, pautou-se nos princípios da Análise de Discurso (AD) desenvolvida por Pêcheux (1969), que se dá a partir da filiação a três áreas do conhecimento, sendo elas a Linguística, utilizando desta a noção de língua como forma não transparente, numa relação simbólica entre o homem e o social; o Marxismo, com o materialismo histórico e a Psicanálise, de onde toma a noção do inconsciente para a constituição do sujeito discursivo.

Pelo princípio da opacidade linguística, a partir das etapas de análise discursiva, partindo do explícito, ou seja, da materialidade linguística, buscou-se chegar ao não-dito. Sendo o discurso objeto da AD, para Pêcheux e Fuchs (1997, p. 82) o que se denomina por discurso é "“efeitos de sentidos' entre os pontos A e B".

Assim, procurou-se estudar os efeitos de sentidos possíveis a partir do funcionamento da ideologia, tendo como base as ideias de Althusser (1974), além de investigar como o interdiscurso e a regularidade atuam na cristalização de sentidos sobre a mulher a partir das piadas do Jornal das Moças na década de 50.

\section{RESULTADOS E/OU DISCUSSÃO (ou Análise e discussão dos resultados)}

A piada a seguir está presente na Revista Jornal das Moças de janeiro de 1952 na seção Troças\&Traços.

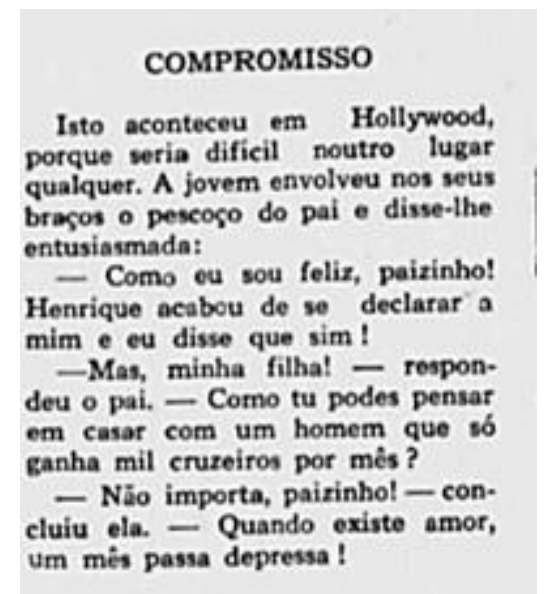

Figura 1- Fonte: Jornal das Moças, janeiro de 1952.

Destaca-se em "Compromisso", como é intitulada a piada, o seguinte enunciado: "isto aconteceu em Hollywood porque seria difícil noutro lugar qualquer". A partir dele, produz-se o sentido de que o casamento a partir do sentimento amoroso é bastante difícil de acontecer na realidade. Esse sentido pode ser construído a partir dos já-ditos que a revista traz sobre os astros e estrelas de Hollywood: para manter a ordem dos lugares sociais no Brasil, a revista não deixa de frisar que alguns caracteres dos costumes estrangeiros não cabem para a sociedade brasileira.

Seguindo, o próximo enunciado diz respeito a notícia que a filha dá ao pai: "- Como sou feliz, paizinho! Henrique acabou de se declarar a mim e eu disse que sim!”. Aqui, chama atenção a utilização do verbo ser que condiciona o sentido de estabilidade do sentimento de alegria da moça. Ao dizer que é feliz e apresentar, logo depois, que o motivo pelo qual se sente desse modo é o fato de ter aceito o pedido de casamento, a partir do qual a felicidade é garantida, infere-se o funcionamento da ideologia naturalizando a felicidade feminina condicionada ao casamento. Assim, para ser mulher e, mais especificamente, uma mulher feliz, a ideologia trabalha para conduzir os sujeitos-mulheres a ocuparem o lugar social de esposa, constituindo, dessa forma, também um lugar discursivo, a partir da interpelação do indivíduo em sujeito, o que o leva a inscrever-se na Formação Discursiva (FD) com a qual se identifica: em outras palavras, a FD que o constitui enquanto sujeito. 
Pai e filha se inscrevem em uma FD que considera que para a existência de um bom casamento, é necessário que o pretendente tenha uma boa condição financeira, no entanto, podese identificar, a partir da resposta da filha, ao dizer não se importar, pois quando se tem amor um mês passa depressa, um deslocamento do processo de significação (ORLANDI, 2015). Há, aí, o processo polissêmico, segundo o qual os sentidos sempre podem ser outros. Em contrapartida, há a presença de paráfrase que representa o retorno aos espaços do dizer já constituídos. A filha está situada nesse jogo entre paráfrase e polissemia: ao mesmo tempo em que rompe com o sentido de que o casamento só pode ser mantido com uma boa estrutura, retorna à matriz do sentido à medida em que considera o dinheiro necessário à manutenção do matrimônio ao passo que conclui que logo um novo mês irá surgir e, assim, a remuneração do esposo se dará novamente.

A constituição do homem como chefe da família, o que engloba essa responsabilidade em ser principal, senão único - preferencialmente -, provedor das necessidades da esposa e mãe da prole, desencadeia certas representações das mulheres. O recorte a seguir, de uma piada de fevereiro de 1952, também aborda a relação financeira entre os cônjuges:

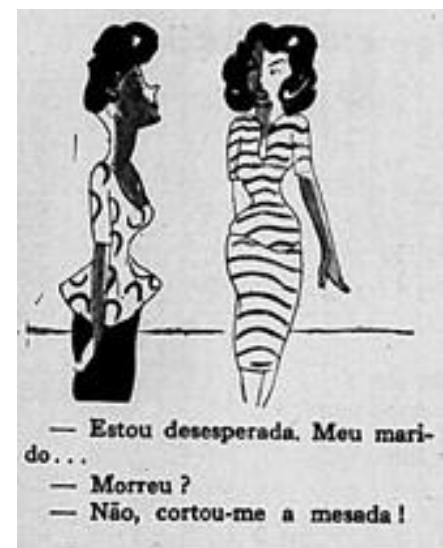

Figura 2 - Fonte: Jornal das Moças, fevereiro de 1952

Ao enunciar o seu desespero e o motivo deste (seu marido cortar-lhe a mesada) observase o pré-construído de que a mulher depende financeiramente do esposo. Na piada, há a presença do já-dito sobre os lugares e papeis dos homens e mulheres. A imagem do casamento nas piadas é, regularmente, passada como infortúnio e fonte de chateações. Conforme Pinsky (2014, p. 32) "O matrimônio só traz infelicidade ao homem e é, quase sempre, um bom investimento para a mulher". O fato da mulher estar desesperada por não poder mais contar com as finanças, a "mesada", do marido silencia o sentido de que a mulher pode ocupar o lugar que designa que ela também pode conseguir dinheiro mediante seu trabalho.

Em coincidência com as condições de produção, leva-se em conta o contexto de desenvolvimento industrial, que contribuiu para o aumento do consumo. Isto se relaciona intimamente a grande parte do conteúdo das revistas femininas: anúncios e propagandas de cosméticos e eletrodomésticos. Assim, retomando-se os dizeres do interdiscurso, ao precisar cortar a "mesada" da esposa, está implícito (não-dito) a necessidade de controle dos gastos realizados por ela, identificando-se, dessa forma, na piada, o não-dito de que são gastadeiras e interesseiras, de forma que o casamento é um mau negócio para o gênero masculino.

\section{CONSIDERAÇÕES FINAIS (ou Conclusão)}

O Jornal das Moças, assim, contribui para difundir a ideologia dominante e manter as concepções sobre mulher, casamento e família que se tinha na época. A voz da revista se inscreve em uma formação discursiva cuja mulher é responsável por manter o matrimônio 
intacto mesmo que, nas piadas, os sentidos possíveis de serem construídos são justamente o do comportamento da mulher como entrave para a paz conjugal. Como afirma Pinsky (2014, p. 33-34) "[...] ] cômico atua como forma de controle e desaprovação de determinadas atitudes ou situações e justifica o pensamento que defende a superioridade do masculino com relação ao feminino", no entanto, a cristalização desses sentidos consequente da regularidade deles atua na construção de estereótipos sobre a feminilidade, da mesma forma que contribuam para manter os lugares sociais e, assim, discursivos, estabelecidos pela ideologia dominante. Nessa interrelação entre língua, história e ideologia, os discursos produzidos pelas piadas do Jornal das Moças também produzem sentidos sobre a construção do sujeito-mulher.

A regularidade encontrada nas piadas do Jornal das Moças retoma sentidos que são levados ao mesmo espaço do dizer, cristalizando-se e construindo estereótipos sobre a feminilidade, que são naturalizados e, por isso, tido como inerentes ao sujeito-mulher ainda na contemporaneidade.

Os resultados alcançados apontam para maior presença de repetição de situações de humor que envolvem mulher e matrimônio (naturalizando a ocupação desse lugar para o sujeito-mulher, o que se relaciona com a formação ideológica que imperava na década de 50), o que, de certa forma, não excluiu as outras representações da mulher que aparecem também nessas piadas as quais também envolvem o casamento.

\section{REFERÊNCIAS}

ALTHUSSER, Louis. Ideologia e Aparelhos Ideológicos do Estado. Lisboa: Presença, 1974. Biblioteca Nacional Digital Brasil. Jornal das Moças. Disponível em: $<$ http://memoria.bn.br/DocReader/docreader.aspx?bib=111031_05\&pasta=ano\%20195\&pesq $=>$. Acesso em: julho de 2018 .

ORLANDI, Eni Puccinelli. Análise de Discurso: princípios e procedimentos. 12 ed. Campinas: Pontes, 2015.

PÊCHEUX, Michel \& FUCHS, C. (1975). "A propósito da análise automática do discurso: atualizações e perspectivas". In: GADET \& HAK (org.). Por uma análise automática do discurso. $3^{\text {a }}$ ed., Campinas: Ed. da Unicamp, 1997, p. 61 - 161.

PÊCHEUX, Michel. "Análise automática do discurso (AAD-69)". In: GADET \& HAK (org.). Por uma análise automática do discurso. $3^{a}$ ed., Campinas: Ed. da Unicamp, 1997, p. 163 252.

PINSKY, Carla Bassanezi. Mulheres dos Anos Dourados. São Paulo: Contexto, 2014. 